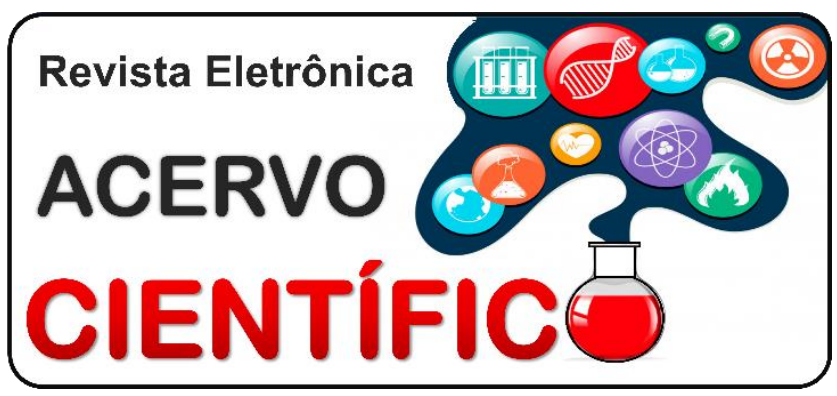

ARTIGO ORIGINAL

Recebido em: 8/2020

Aceito em: $10 / 2020$

Publicado em: 2/2021

\title{
Atitudes e práticas em biossegurança no centro de material e esterilização de um hospital terciário
}

\author{
Attitudes and practices in biosafety in the material and sterilization center of a tertiary \\ hospital
Actitudes y prácticas en bioseguridad en el centro de material y esterilización de un hospital terciario

Arimatéia Portela de Azevedo ${ }^{1,2 *}$, Helen Thaís da Silva Magno ${ }^{1,2}$, Louan Soares de Azevedo ${ }^{2}$, Francisca Parente Medeiros ${ }^{1,2}$, José Geraldo Santos de Araújo ${ }^{1,2}$, Maria Solenilda de Oliveira Corrêa $^{1,2}$, Joyce Barros Serra ${ }^{1,2}$, Maria Gracieide Filha Santarém Andrade ${ }^{1,2}$, Marina Rocha Gomes de Freitas ${ }^{1,2}$, Valdiza Pimentel Jesus da Silva ${ }^{1,2}$.

Resumo: Registrar o conhecimento, atitudes e práticas sobre biossegurança e comportamento em ambiente crítico dos servidores de uma Central de Material Esterilizado (CME) em um hospital referência em infectologia. Tratou-se de um estudo prospectivo, descritivo onde a coleta de dados se deu através de um questionário aplicado antes de um treinamento e outro após o treinamento e um inquérito observacional. Foi evidenciado que $10 \%$ dos servidores deste setor não tinham entendimento sobre comportamento em ambiente crítico, 30\% demostraram nos testes que não sabiam utilizar de forma correta os Equipamentos de Proteção Individual e Coletiva (EPI's e EPC's) e 10\% erraram as questões sobre limpeza, desinfecção e esterilização de alto nível de artigos críticos. Todos relataram nunca ter participado de algum treinamento sobre essa temática. Foi evidenciado, durante o inquérito observacional, servidores sem EPI's durante a lavagem dos instrumentais contaminados, mesmo havendo o equipamento no setor. $O$ resultado do questionário mostrou que é necessário intensificar as visitas de auditorias internas para averiguação de não conformidades referentes ao servidor e ao ambiente e também exortar a equipe à adesão ao uso dos EPl's/EPC's.

Palavras-chave: Biossegurança, Equipamento de proteção individual, Educação em saúde.

\begin{abstract}
Record the knowledge, attitudes and practices about biosafety and behavior in a critical environment of the servers of a Sterilized Material Center (SMC) in a reference hospital in infectiology. It was a prospective, descriptive study in which data collection took place through a questionnaire applied before training and another after training and an observational survey. It was evidenced that $10 \%$ of the servers in this sector had no understanding of behavior in a critical environment, $30 \%$ demonstrated in the tests that they did not know how to use the Individual and Collective Protection Equipment (PPE's and CPE's) correctly, and $10 \%$ were wrong. questions on high-level cleaning, disinfection and sterilization of critical
\end{abstract}

1 Fundação de Medicina Tropical Dr. Heitor Vieira Dourado, Manaus - AM. *E-mail: arimateia@fmt.am.gov.br

2 Universidade Nilton Lins, Manaus - AM. 
articles. All reported never having participated in any training on this topic. During the observational survey, servers without PPE were found during the washing of contaminated instruments, even with the equipment in the sector. The result of the questionnaire showed that it is necessary to intensify the visits of internal audits to investigate non-conformities regarding the server and the environment and also to urge the team to adhere to the use of PPE's / EPC's.

Keywords: Biosafety, Individual protection equipment, Health education.

Resumen: Registrar los conocimientos, actitudes y prácticas sobre bioseguridad y comportamiento en un entorno crítico de los servidores de un Centro de Material Esterilizado (CME) en un hospital de referencia en infectología. Se trató de un estudio descriptivo prospectivo en el que la recolección de datos se realizó mediante un cuestionario aplicado antes del entrenamiento y otro posterior al entrenamiento y una encuesta observacional. Se evidenció que el $10 \%$ de los servidores de este sector no tenían comprensión de comportamiento en un ambiente crítico, el 30\% demostró en las pruebas que no sabían utilizar los Equipos de Protección Individual y Colectiva (EPI's y EPC's) preguntas correctamente y un $10 \%$ de errores sobre limpieza, desinfección y esterilización de alto nivel de artículos críticos. Todos declararon no haber participado nunca en ninguna formación sobre este tema. Durante el relevamiento observacional, se encontraron servidores sin EPP durante el lavado de instrumentos contaminados, incluso con los equipos del sector. El resultado del cuestionario mostró que es necesario intensificar las visitas de auditorías internas para investigar no conformidades con respecto al servidor y el medio ambiente y también para instar al equipo a adherirse al uso de EPl's / EPC's.

Palabra clave: Bioseguridad, Equipo de protección personal, Educación sanitaria.

\section{INTRODUÇÃO}

As discussões envolvendo a proteção e segurança dos trabalhadores iniciou em 1970 devido ao alto número de infecções acidentais de trabalhadores envolvidos com pesquisa em organismos geneticamente modificados. Desde então, o conceito de biossegurança foi desenvolvido e introduzido pela comunidade cientifica, para adoção de processo de boas práticas em laboratórios e pela preocupação da segurança, do ambiente e da saúde humana, trazendo resultados e avanços positivos (ANVISA, 2012; AZEVEDO AP, et al., 2018).

Os profissionais da área da saúde, estão constantemente sob o risco de sofrer acidentes ocupacionais, pois o hospital é considerado uma grande área de riscos de acidentes, devido à complexidade das atividades desenvolvidas no local (JUNIOR ASA, et al., 2015).

Estão expostos a riscos físicos, químicos, ergonômicos, psicossociais e biológicos, que podem causar acidentes e doenças ocupacionais, gerados por diversos motivos como: número insuficiente de trabalhadores, sobrecarga de trabalho, jornadas longas, plantões noturnos, desgaste físico, emocional e a capacitação técnica deficiente (BEZERRA VS, et al., 2015).

Os riscos de acidentes com exposição a material biológico são cada vez mais proeminentes, devido ao contato contínuo com agentes biológicos. Tal realidade está relacionada a práticas indevidas no uso de Equipamentos de Proteção Individual (EPI) e Equipamentos de Proteção Coletiva (EPC), bem como à subutilização de estratégias de proteção contra agentes contaminantes, como indisponibilidade dos equipamentos de proteção, fiscalização e instrução ineficazes, descarte inadequado de perfuro cortantes, entre outras insalubridades encontradas no serviço de saúde (ROCHA THL, et al., 2020).

É bem evidente que a biossegurança, como ciência indispensável às áreas da saúde, compreende os protocolos e condutas técnico-científicas e educacionais, cuja doção pelos profissionais da área de saúde ou afins, tem como objetivo evitar acidentes e contaminação cruzada em ambientes clínicos, ambulatoriais e/ou hospitalares (SANTOS IBC, et al., 2017; MELO TRNB, et al., 2020). 
Os EPl's são dispositivos ou produtos, destinados a proteção dos riscos que ameaça a segurança a saúde do trabalhador. Ainda existe comportamentos relacionado com à cultura de não se proteger nas situações de exposição a material biológico. Por isso, é necessário desenvolver ações de capacitação para os trabalhadores de forma continuada, para agregar conhecimento, modificar as condutas e os comportamentos inadequados (SILVA LCP e JULIANE CMCM, 2017; LORO MM e ZEITOUNE, 2017).

Segundo a Resolução da Diretoria Colegiada (RDC) n 15 de 15 de março de 2012, a Central de Material de Esterilização (CME), "é uma Unidade funcional destinada ao processamento de produtos para saúde dos serviços de assistência médico-odonto-hospitalares" para que haja um funcionamento ideal, depende de um conjunto de medidas como estrutura física adequada, equipe capacitada, recursos de materiais e equipamentos próprios para a operacionalização em todas as etapas do processo (RIBEIRO JMS, et al., 2019).

No CME a biossegurança torna-se um desafio para os profissionais da saúde, em suas rotinas de trabalho estão envolvidos em diversos riscos, pois são responsáveis pelo processamento de produtos para saúde, que inclui: limpeza, preparo, esterilização, armazenamento e distribuição, garantindo segurança ao paciente e permitindo o uso de materiais em condições adequadas (BORGHETI SP, et al., 2016).

O CME é considerado uma área crítica por processar artigos resultantes de intervenções clínicas e cirúrgicas na qual a qualidade dos serviços realizados está diretamente ligada à qualidade e à segurança dos produtos processados (BRASIL, 2010; AQUINO JM, et al., 2014).

A partir da concepção de que a educação continuada é fundamental para qualificar o indivíduo para a prática assistencial direta ou indireta, é imprescindível maiores investimentos em treinamentos intra hospitalares, oportunizando recrutar todos os funcionários da Central, com enfoque na implementação de ações concretas voltadas principalmente ao processamento correto dos artigos médico-hospitalares e ao manuseio de inovações tecnológicas utilizadas para tornar o serviço mais hábil, devendo ser realizadas com periodicidade trimestral, melhorando assim a qualidade do serviço prestado (ROCHA THL, et al., 2020).

As pesquisas mostram que a falta de treinamento, capacitação, desconhecimento dos riscos, inadequação do ambiente físico, escassez de materiais em quantidade e qualidade, quantidade de trabalhadores insuficientes a desorganização do próprio trabalho pode favorecer a exposição a riscos ocupacionais e também gerar sobrecarga das atividades realizadas (COSTA CCP, et al., 2015; BORGHETI et al., 2016).

Mediante tudo que foi referenciado acima, o objetivo principal desse estudo foi registrar a percepção dos servidores do centro de material e esterilização de um hospital referência em infectologia no Amazonas sobre biossegurança e comportamento em ambiente crítico.

\section{MÉTODOS}

O presente estudo foi do tipo prospectivo, descritivo com abordagem qualitativa, onde pretendeu-se registrar, descrever e analisar as informações sobre percepção dos servidores do CME sobre biossegurança e comportamento em ambiente crítico.

A coleta de dados foi realizada através de um pré e pós-teste com 10 perguntas para avaliar 0 conhecimento dos colaboradores sobre biossegurança antes e após orientações dispensadas durante um encontro previamente agendado. Foi realizada a análise do conteúdo seguido de duas etapas: Primeira etapa: foi aplicado um questionário com 10 perguntas para avaliar a percepção do grupo sobre biossegurança e comportamento em ambiente crítico. Em seguida foi realizado um treinamento por meio de exposição oral dialogada, Cases, Leitura orientada, investigação e grupos de debates sobre situações percebidas na prática, para sensibilizar os colaboradores sobre os riscos que estão expostos. Após o treinamento o mesmo questionário foi aplicado novamente para averiguar se o treinamento foi efetivo e se houve obtenção de conhecimento. 
$\mathrm{Na}$ segunda etapa foi realizado inquérito observacional para investigar a efetividade das ações realizadas e verificar se houve mudanças no padrão de comportamento. Durante o inquérito observacional, o pesquisador (a) se posicionou dentro da CME, e sem ser percebido, fez anotações do comportamento dos servidores durante as atividades ali desempenhadas. Observou-se se as medidas de biosseguranças estavam sendo praticadas. Durante o período de coleta de dados foram observadas as variáveis que trouxeram informações sobre o comportamento dos colaboradores do CME.

A pesquisa foi avaliada e aprovada pelo Comitê de Ética em Pesquisa-CEP, de acordo com a resolução 466/12 do Ministério da Saúde, sob o CAAE 75883317.1.0000 0005, com comprovante N. 105127/2017.As informações das fichas devidamente preenchidas foram tabuladas no programa Excel® 2010 e analisados de forma estatística através do software live $R$ versão $3.0{ }^{\circledR}$. O local onde foi realizada a pesquisa foi o CME de um hospital universitário, terciário, referência em doenças infectocontagiosas no Amazonas.

\section{RESULTADOS}

Foram analisados 28 testes escritos aplicados durante um treinamento com os servidores CME, sendo 14 pré e 14 pós-testes. Posteriormente, foi realizada busca ativa de não conformidade durante um inquérito observacional para averiguar se o que foi ensinado estava de fato sendo colocado em prática.

Dos 14 servidores que trabalham neste setor, 28,5\% eram enfermeiros e $64,3 \%$ eram técnicos de enfermagem e $7,3 \%$ eram servidores da higienização e limpeza, todas do gênero feminino, com idades entre 23 a 63 anos, sendo a média de idade de 41 anos.

Durante o período da coleta dos dados, todos os servidores relataram nunca ter participado de algum treinamento ou capacitação sobre biossegurança e comportamento em ambiente crítico dentro do CME e consideram que seu trabalho é desvalorizado e pela falta de conhecimento da importância desse setor pelos colegas de trabalho, que presta uma assistência indireta ao paciente e contribui de forma efetiva para a redução da infecção hospitalar.

Em relação a percepção dos servidores do CME da FMT/HVD sobre biossegurança e comportamento em ambiente crítico registrado nos testes escritos, evidenciou-se que, no pré-teste os enfermeiros acertaram $85 \%$ das questões e os técnicos acertaram apenas $72 \%$. Vale ressaltar que os conhecemos sobre biossegurança e comportamento em ambientes críticos devem ser bem evidentes entre todos com membros da equipe. Essa diferença no conhecimento pode ter acontecido, provavelmente, por falta de compromisso dos enfermeiros em treinar suas equipes ou em virtude da grande rotatividade de servidores no setor.

Foi aplicado um teste escrito, com linguagem mais simples e de fácil compreensão para os servidores de nível elementar como é o caso dos agentes de serviços gerais. O resultado mostrou que houve apenas $55 \%$ de acerto. E propicio enfatizar que esse percentual de acerto pode ter sido influenciado pela falta de compreensão das perguntas ou porque muitos destes servidores nunca trabalharam em ambientes hospitalar e não tiveram oportunidade de receber instruções sobre como se comportar nesses ambientes.

Após o treinamento foi aplicado, para todos os servidores, um pós teste para averiguação da nova percepção e na tentativa de mensurar o nível de aprendizagem sobre biossegurança. Houve um aumento nos acertos de $89,3 \%$ em relação ao pré teste. Foi evidenciado que nem todos os servidores tinham conhecimento dos tipos de EPI's que deveriam ser utilizados em cada setor. Houve considerável melhora no aprendizado após o treinamento. O aperfeiçoamento do conhecimento foi possível após o esclarecimento de dúvidas sobre as medidas de biossegurança em cada área.

É de fundamental importância que os trabalhadores conheçam os EPI's que devem ser utilizados durante cada atividade realizada no seu setor de trabalho e compreendam quais os riscos ocupacionais a que estão expostos, o comportamento de não utilizar ou utilizá-los de maneira incorreta influencia diretamente na segurança dos trabalhadores, colocando-os em situação de risco (FREIXO J e ROCHA A, 2014). 
Para reduzir ou prevenir a exposição com material biológico, os treinamentos periódicos são recomendados com o objetivo de orientar os trabalhadores sobre medidas de biossegurança e uso de adequado dos EPI's (AZEVEDO AP, et al., 2019).

A maioria dos profissionais acreditam que o risco está diretamente ligado às atividades exercidas no CME pois sabem identificar corretamente os EPI's necessários para realização das atividades e a maneira correta de utilizá-los, porém a maioria não sabe reconhecer as situações de riscos as quais estão expostos (FEIXO J e ROCHA A, 2014; STANGANELLI NC, et al., 2015).

Os saneantes utilizados em Centrais de Esterilização para desinfecção e esterilização de alto nível, quando inalados ou em contato direto com a pele e mucosas podem causar danos sérios. Portanto, o fato de haver desconhecimento da equipe sobre essas informações (Tabela 1), pode trazer consequências deletérias irreversíveis para a saúde destes servidores.

Tabela 1 - Descrição dos temas abordados no treinamento e as questões que mais demonstraram desconhecimento observado no pré e pós-teste.

\begin{tabular}{lccc}
\hline Variáveis & $\begin{array}{c}\text { Erros no pré- } \\
\text { teste }\end{array}$ & $\begin{array}{c}\text { Acertos no pós- } \\
\text { teste }\end{array}$ & $\begin{array}{c}\text { Avanço no } \\
\text { aprendizado }\end{array}$ \\
\hline Questionamentos & $\%$ & $\%$ & $\%$ \\
\hline Conhecimento sobre as áreas da CME. & 10 & 100 & 90 \\
Relacionado ao uso de EPI's. & 30 & 95 & 60 \\
Relacionado ao manejo seguro da autoclave. & 15 & 99 & 84 \\
$\begin{array}{l}\text { Sobre limpeza, desinfecção e esterilização de } \\
\text { artigos críticos. }\end{array}$ & 10 & 95 & 85 \\
$\begin{array}{l}\text { Sobre os saneantes utilizados para } \\
\text { desinfecção e esterilização de alto nível. }\end{array}$ & 08 & 100 & 92 \\
\hline
\end{tabular}

Fonte: Azevedo AP, et al., 2020.

A Agência Nacional de Vigilância Sanitária (ANVISA), através da RDC no 15/2012, estabelece os requisitos de boas práticas para o processamento dos produtos para saúde, enquanto que a RDC no 50/2002, dispõe sobre a infraestrutura física dos estabelecimentos, o regulamento técnico para planejamento, programação, elaboração e avaliação de projetos físicos.

Durante o inquérito observacional identificamos que os setores não possuem iluminação adequada, equipamentos de transporte com rodízio e controle de temperatura, há um fluxo intenso de pessoas de outras áreas do hospital para dentro do $\mathrm{CME}$, o mesmo fica ao lado do centro cirúrgico e há somente uma entrada para os dois setores, além disso, o acesso para o expurgo e a sala de distribuição ocorre pelo preparo que é a única entrada e saída dos setores.

A iluminação adequada e os equipamentos de transporte com rodízio são essenciais para evitar acidentes e realizar o transporte dos materiais adequadamente, a monitorização e avaliação dos parâmetros de temperatura devem permanecer entre $18^{\circ}$ e $22^{\circ} \mathrm{C}$ no expurgo, e entre $20^{\circ}$ e $24^{\circ} \mathrm{C}$ na sala de preparo e esterilização (BRASIL, 2005; BORGHETI SP et al., 2016).

Ambientes com temperaturas elevadas são ideais e justificam-se porque as bactérias se desenvolvem em altas temperaturas, enquanto que as baixas temperaturas podem diminuir o crescimento bacteriano principalmente nas superfícies e embalagens (JUNIOR ASA, et al., 2015; ROCHA THL, et al., 2020).

A área física desse setor deve ser projetada com fluxo unidirecional, para que seja evitado o cruzamento de material limpo com material contaminado e vice-versa, além do fluxo de funcionários, é necessário que haja um local apropriado para a manipulação de produtos químicos que impliquem riscos à segurança e saúde do trabalhador devendo a área ser sinalizada (BEZERRA VS, et al., 2015).

Em relação à estrutura física conforme preconizado pelo Ministério da Saúde por meio da RDC 15 e 50, observou-se neste estudo que dos 17 itens primordiais apontados pelo Ministério da Saúde, 29,4\% não estavam adequados (Quadro 1). 
Quadro 1 - Inadequações na estrutura e falta de equipamentos percebidos e registradas durante o inquérito observacional.

\begin{tabular}{|lc|}
\hline Estrutura física/equipamentos & Status \\
\hline Exaustor & Dispõe \\
\hline lluminação adequada & Não dispõe \\
\hline Fluxo unidirecional & Não dispõe \\
\hline Prateleiras ou cestos aramados & Dispõe \\
\hline Equipamentos de transporte com rodízio & Não dispõe \\
\hline Monitorização da climatização do ambiente & Não dispõe \\
\hline Área de recepção, descontaminação e separação de materiais & Dispõe \\
\hline Local de lavagem das mãos com dispensadores de germicidas & Dispõe \\
\hline Área para lavagem e descontaminação & Dispõe \\
\hline Bancada com uma cuba para limpeza e outra para enxágue & Dispõe \\
\hline Área para recepção de roupa limpa & Não dispõe \\
\hline Área para preparo de materiais e roupa limpa & Dispõe \\
\hline Área para esterilização física & Dispõe \\
\hline Sala de armazenagem e distribuição de materiais esterilizados & Dispõe \\
\hline Sala administrativa & Dispõe \\
\hline Sala para Deposito de material de limpeza (DML) & Dispõe \\
\hline Vestiário de barreira (exclusivo para CME) & Dispõe \\
\hline
\end{tabular}

Fonte: Azevedo AP, et al., 2020.

O trabalho no CME pode ser tão, ou mais insalubre que as demais unidades, os profissionais estão expostos a inúmeros riscos físicos e mentais, pela sobrecarga de trabalho, pela inadequação física da instituição ou pela falta e adesão aos EPI's (JUNIOR ASA, et al., 2015; SILVA SR, et al., 2018).

Muitos hospitais brasileiros podem estar vivenciando essas mesmas dificuldades. Mas vale ressaltar que a instituição onde ocorreu o estudo está em andamento com um projeto de construção de um novo ambiente para a Central de Material e Esterilização levando em consideração todas as leis e normas que regem este setor.

Este local deve ter uma área para lavagem das mãos com torneiras que dispensem contato com as mãos no fechamento da água sendo de suma importância, pois as mãos são fonte de transferência de micro-organismos, na área suja evita infecções aos trabalhadores e na área limpa sendo essencial para proteção dos usuários dos serviços (COSTA CCP, et al., 2015; RIBEIRO JMS, et al., 2019).

Autores dizem que as não conformidades relacionadas à estrutura física inadequada como: ambiente pouco arejado, lavatório de acionamento manual, ausência de controle diário de temperatura e dos materiais estéreis, acesso ao setor restrito e o uso incompleto de EPI, interfere diretamente na qualidade do serviço prestado e na segurança dos servidores (SANTOS IBC, et al., 2017; MAZUTTI WJ et al., 2018).

O espaço físico inadequado para exercer as atividades rotineiras do CME, gera um desconforto que pode causar riscos ergonômicos, a infraestrutura recomendada pelo ministério da saúde propicia mais comodidade aos colaboradores (RIBEIRO JMS, et al., 2019).

Foi evidenciado, também, durante o inquérito observacional, servidores sem roupa privativa, gorro, máscaras de proteção facial, pró-pé, óculos de proteção, avental impermeável durante a lavagem dos instrumentais contaminados. No momento o empacotamento dos materiais também não foi observado a utilização de luvas de procedimento para o manuseio dos artigos. Quanto aos cuidados durante a descarga da autoclave, não foi evidenciado a utilização de luvas térmicas. Os servidores alegavam não haver na unidade. A RDC 15 enfatiza que tal equipamento de proteção contra o calor deve estar a disposição do servidor.

Esses equipamentos oferecem condições de proteção, porém o uso inadequado ou a falta deles geram riscos a saúde do trabalhador que estará exposto à contaminação por material biológico (AZEVEDO AP, et al., 2019). 


\section{CONCLUSÃO}

Mesmo sabendo que os Equipamentos de Proteção Individual e Coletivos EPI's/EPC's são importante para proteger os profissionais individualmente reduzindo qualquer tipo de ameaça ou risco para o trabalhador e mesmo sendo obrigação dos supervisores e da empresa garantir que os profissionais façam o uso adequado dos equipamentos de proteção individual, percebeu-se uma expressiva não adesão ao uso destes equipamentos. Quanto as não conformidades relacionadas a estrutura, equipamentos inclusive ao comportamento dos servidores, foi observado, também, que há esforço dos gestores para manter o ambiente salubre eliminando inconformidades no ambiente físico e promovendo treinamento para melhorar as atitudes dos profissionais em relação a biossegurança. Mas, ainda é evidente a necessidade de mais investimentos em ações de educação permanente para incentivar a adesão e o uso de EPI's e promover mudanças na prática dos servidores que atuam em setores críticos.

\section{AGRADECIMENTOS}

Agradecemos a Fundação de Medicina Tropical Dr. Heitor Heitor Vieira Dourado por permitir a realização do estudo.

\section{REFERÊNCIAS}

1. AGÊNCIA NACIONAL DE VIGILÂNCIA SANITÁRIA. Resolução - RDC no 15, de 15 de março de 2012. Dispõe sobre requisitos de boas práticas para o processamento de produtos para saúde e dá outras providências. Brasília, DF: Anvisa, 2012.

2. AQUINO JM, et al. Centro de material e esterilização: acidentes de trabalho e riscos ocupacionais. Rev. SOBECC, $2014 ; 19(3): 148-154$.

3. AZEVEDO AP, et al. Educação em saúde para acompanhantes de pacientes internados. Rev. enferm. UFPE on line., 2018; 12(4): 1168-73.

4. AZEVEDO AP, et al. Acidentes com exposição a material biológico atendidos em um hospital. Rev. enferm. UFPE online, 2019: (13):2390-25.

5. BEZERRA VS, et al. Riscos biológicos enfrentados pelos enfermeiros na Unidade de Terapia Intensiva. Rev. Pre. Infec e Saúde, 2015;1(3):18-26.

6. BRASIL. MINISTÉRIO DA SAUDE. Biossegurança em saúde: prioridades e estratégias de ação. Ministério da Saúde, Organização Pan-Americana da Saúde. - Brasília, 2010.

7. BRASIL. Ministério do Trabalho e Emprego. Norma Regulamentadora oㅜ 32. Portaria ํㅡ 485, de 11 de novembro de 2005. Estabelece as diretrizes básicas para a implementação de medidas de proteção à segurança e à saúde dos trabalhadores dos serviços de saúde, bem como daqueles que exercem atividades de promoção e assistência à saúde em geral. Brasília, DF: MTE, 2005.

8. COSTA CCP, et al. O trabalho na central de material: repercussões para a saúde dos trabalhadores de enfermagem. Rev enferm UERJ, 2015: 23(4):533-39.

9. FREIXO J, ROCHA Á. Arquitetura de Informação de Suporte à Gestão da Qualidade em Unidades Hospitalares. RISTI, 2014; 14.

10. JÚNIOR ASA, et al. Risco biológico no contexto da prática de enfermagem: uma análise de situações favorecedoras. Revista de epidemiologia e controle de infecção. Rev Epidemiol Control Infect, 2015;5(1):42-46.

11. MAZUTTI WJ, et al. Acidentes perfurocortantes envolvendo material biológico: o dizer e o fazer de estudantes de um curso de graduação em Odontologia. Revista da ABENO, 2018; 18(4): 21-30.

12. MIRANDA AR, et al. O processo de trabalho no centro de material e esterilização: percepção da equipe de enfermagem. Revista Científica de Enfermagem (RECIEN), 2019; 9(27): 33-45.

13. BORGHETI SP, et al. Biossegurança no centro de materiais e esterilização: dúvidas dos profissionais. REV. SOBECC, 2016; 21(1): 3-12.

14. SANTOS IBC, et al. Equipamentos de proteção individual utilizados por profissionais de enfermagem em centros de material e esterilização. Rev. SOBECC, 2017; 22(1): 36-41.

15. STANGANELLI NC, et al. A utilização de equipamentos de proteção individual entre trabalhadores de enfermagem de um hospital público. Cogitare Enferm. 2015;20(2):345-51.

16. SILVA LCP, JULIANI CMCM. O risco ocupacional para profissionais da Estratégia Saúde da Família. Revista Brasileira de Pesquisa em Saúde/Brazilian Journal of Health Research. Vitória,2016;18(2): 52-59.

17. SILVA SR, et al. Implantação de um software para controle da central de esterilização do curso de Odontologia da Universidade Positivo. Revista da ABENO,2018; 18(3):53-61.

18. AGENCIA NACIONAL DE VIGILÂNCIA SANITÁRIA. Regulamento Técnico para planejamento, programação, elaboração e avaliação de projetos físicos de estabelecimentos assistenciais de saúde. Resolução - RDC nำ50, de 21 de fevereiro de 2002.

19. RIBEIRO JMS, et al. Avaliação do conhecimento da equipe de enfermagem no processo de esterilização de materiais cirúrgicos. Revista Eletrônica Acervo Saúde (REAS), 2019; 11(15): e1177.

20. ROCHA THL, et al. Falhas no uso de equipamentos de proteção individual pelos Profissionais de saúde: revisão de literatura. REAS/EJCH, 2020;12(11): e4035. 